\title{
Expressando conceitos de qualidade em Xavante: adjetivos ou verbos?
}

\author{
Expressing concepts of quality in Xavante: adjectives or verbs? \\ Adriana MACHADO ESTEVAM* \\ Université du Québec à Montréal (UQAM)
}

\begin{abstract}
RESUMO: O objetivo deste trabalho é discutir a categoria dos lexemas que expressam conceitos de qualidade em Xavante para mostrar que, apesar destes lexemas apresentarem propriedades semânticas características dos adjetivos, tratam-se de lexemas verbais. Com esse propósito, veremos num primeiro momento que, além de compartilharem propriedades semânticas, estes lexemas possuem propriedades morfossintáticas que os caracterizam de maneira formal como uma classe de palavras, mas que esta classe não pode ser considerada como sendo de adjetivos, se definirmos os adjetivos como lexemas cuja função primordial é atuar como núcleo de um sintagma adjetival desempenhando a função de atributo num sintagma nominal. Em seguida serão apresentadas as propriedades morfossintáticas dos lexemas verbais e nominais, deixando claro que os lexemas em questão formam uma subclasse verbal.
\end{abstract}

PALAVRAS-CHAVE: Categorização. Adjetivos. Morfossintaxe. Xavante.

ABSTRACT: The aim of this article is to discuss a category of lexemes that express concepts of quality in Xavante in order to show that, despite showing semantic properties typical of adjectives, the lexemes in question are verbal. With this in mind, we will show first that, not only do the lexemes under investigation share semantic properties, they also exhibit morphosyntactic properties that characterize them as a formal class. However, this class cannot be considered as an adjectival class if adjectives are defined as heads of adjectival phrases acting as attributes inside a nominal phrase. We will then present the morphosyntactic properties of verbal and nominal lexemes, which clearly show that the lexemes in question form a subclass of verbs.

KEYWORDS: Categorization. Adjectives. Morphosyntax. Xavante.

\section{Introdução}

A linguística descritiva e tipológica tem mostrado, no que diz respeito à questão das classes de palavras, a importância dos critérios internos que cada língua oferece para estabelecer uma categorização dos itens de seu léxico em partes do discurso e a dificuldade (para não dizer a impossibilidade) de se identificar critérios universais para definir certas categorias, como a do adjetivo. Esta questão é particularmente relevante em Xavante ${ }^{1}$, que apresenta uma classe de

\footnotetext{
* Doutorado em Linguística pela Université Paris 7 Denis Diderot. Atualmente em pós-doutorado na Université du Québec à Montréal (Département de Linguistique, Faculté des Sciences Humaines), Montréal (Canadá). Email para contato: dri.mcst@gmail.com.

${ }^{1}$ Língua do grupo jê, do tronco macro-jê, falada por aproximadamente 15000 pessoas espalhadas em terras indígenas
} 
lexemas que podem funcionar, de um ponto de vista semântico, como modificadores nominais. Tentaremos mostrar aqui que esta propriedade não é suficiente para estabelecermos uma classe de adjetivos, pois as propriedades formais dos lexemas em questão são todas verbais.

O artigo está organizado da seguinte forma. Num primeiro momento são apresentados os lexemas de sentido adjetival e suas propriedades morfossintáticas. Em seguida são expostas as propriedades morfológicas (flexão e composição) e sintáticas (funções desempenhadas) que definem os lexemas verbais. A seção seguinte aborda a flexão, a composição e as funções sintáticas características dos lexemas nominais. Uma hipótese diacrônica é sugerida antes de concluírmos com algumas considerações finais.

\section{Lexemas que expressam qualidades}

\subsection{Apresentação}

Observa-se em Xavante uma classe de lexemas que referem aos tipos semânticos que, segundo Dixon (1982, p. 16), estão associados à categoria dos adjetivos nas línguas onde esta categoria existe. Seguem abaixo alguns exemplos desta classe, em função dos tipos semânticos em questão.

$\begin{array}{lllllll}\text { dimensão } & \text { propriedade física } & \text { cor } & \text { idade } & \text { valor } & \text { velocidade } & \text { propensão humana } \\ \text { sa?ẽtẽ } & \text { pire } & \text { pré } & \text { Prada } & \text { wẽ } & \text { waptu } & \text { sõprub } \\ \text { 'grande' } & \text { 'pesado' } & \text { 'vermelho' } & \text { 'velho' } & \text { 'bom' } & \text { 'rápido' } & \text { 'generoso' } \\ \text { Prare } & \text { tede } & \text { rã } & \text { té } & \text { pese } & & \text { sahi } \\ \text { 'pequeno' } & \text { 'duro' } & \text { 'branco' } & \text { 'novo' } & \text { 'perfeito' } & & \text { 'bravo' } \\ \text { pa } & \text { se } & \text { Prãdö } & & \text { uptabi } & \text { wa?a } \\ \text { 'comprido' } & \text { 'doce' } & \text { 'preto' } & & \text { 'verdadeiro' } & \text { 'preguiçoso' } \\ \text { ?rudu } & \text { wa?ro } & & & & \text { sita } \\ \text { 'curto' } & \text { 'quente' } & & & & & \text { 'exibido' }\end{array}$

Estes lexemas - que chamaremos por precaução de 'lexemas com sentido adjetival' formam uma classe não só semântica como também morfossintática: uma de suas propriedades formais, como mostra o exemplo (1), é de poder ocupar uma posição seguinte a do nome para determiná-lo. Neste exemplo, o lexema uptabi 'verdadeiro, autêntico' segue o nome damreme 'língua': à primeira vista, poderia tratar-se de um adjetivo em função atributiva.

no leste do Mato Grosso, na região da Serra do Roncador e dos rios Culuene, das Mortes, Couto de Magalhães, Batovi e Garças. Nossos dados foram coletados na Terra Indígena São Marcos. Outros trabalhos efetuados na mesma área - mas que têm uma visão diferente sobre o problema tratado aqui - são Lachnitt (1999) e Oliveira (2007). 


\begin{tabular}{|c|c|c|c|c|c|}
\hline Romnhoré?wai & $\mathrm{ma}$ & hã & da-mreme & uptabi & si \\
\hline aluno & DAT & PE & $3^{\mathrm{a}} \mathrm{GNQ}$-língua & verdadeiro & somente \\
\hline waihu?u & zaPra & waraba & mono & $!$ & \\
\hline$\left[3^{\mathrm{a}} \mathrm{ABS}\right]$ ensinar & PL & $\mathrm{COL}$ & ITR & & \\
\hline
\end{tabular}

'Ensinem para os alunos somente a nossa verdadeira língua!'

No entanto, uma série de propriedades nos leva a pensar que um morfema como uptabi ‘(ser) verdadeiro' em (1) não é o núcleo de um sintagma adjetival dependente de um nome como damreme 'língua' em função de atributo.

De modo geral, observa-se que a frequência de uso de um lexema com sentido adjetival após um nome é muito baixa; visto que estes lexemas formam uma classe extensa, esperaría-se que o uso destes fosse mais frequente no caso de serem adjetivos.

Existem também restrições sintáticas, como a impossibilidade de variar a ordem entre o nome e o lexema com sentido adjetival, assim como coordenar dois lexemas com sentido adjetival: para que o lexema com sentido adjetival apareça em outra posição ou faça parte de uma coordenação, ele deve ser usado numa forma específica. Ou seja, é importante notar o contraste entre uma forma simples do lexema com sentido adjetival e uma forma complexa, onde o mesmo é prefixado pelo morfema $\tilde{\imath}$-, como ilustrado nos exemplos a seguir.

Em (2.a) vê-se que o lexema com sentido adjetival Prãihö 'alto', na sua forma simples, não pode anteceder o nome aibö 'homem'. No entanto, prefixado pelo morfema $\tilde{l}$ - em (2.b), a ordem das palavras pode ser invertida.

$\begin{array}{ll}\text { Wa } & \text { Pmadö } \\ \text { EGO } & {\left[3^{\mathrm{a}} \mathrm{ABS}\right] \text { ver }}\end{array}$

aibö

Prãihö.

'Eu vi um homem alto.'

\begin{tabular}{|c|c|c|c|}
\hline (2.a.ii) & * wa & Pmadö & Prãihö \\
\hline & EGO & {$\left[3^{\mathrm{a}} \mathrm{ABS}\right]$ ver } & alto \\
\hline
\end{tabular}

$\begin{array}{lllll}\text { (2.b.i) } & \text { Wa } & \text { Pmadö } & \text { aibö } & \text { i-Prãihö. } \\ & \text { EGO } & {\left[3^{\mathrm{a} A B S}\right] \text { ver }} & \text { homem } & \text { ĩ-alto }\end{array}$

'Eu vi um homem alto.'
(2.b.ii) Wa
Pmadö
̃-?rãihö aibö. 
EGO $\quad\left[3^{\mathrm{a}} \mathrm{ABS}\right] \mathrm{ver}$ i-alto homem

'Eu vi um homem alto.'

Nos seguintes exemplos, observa-se que a coordenação de dois lexemas com sentido adjetival é agramatical quando estes estão na sua forma simples, e problemática mesmo prefixados pelo morfema $\tilde{l}$-. Assim, para qualificar o mesmo homem de Prãihö 'alto' e wahi 'magro', os locutores preferem usar dois constituintes separados, como mostra (3.a), onde o

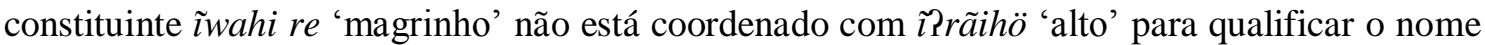
aibö 'homem', mas está funcionando como uma segunda oração, juxtaposta à primeira. Esta construção é preferida àquela ilustrada em (3.b), onde a coordenação dos dois lexemas marcados pelo prefixo $\tilde{l}$ - é julgada pouco natural. Já a coordenação dos dois lexemas na sua forma simples, como em (3.c), é agramatical.

$\begin{array}{llllllll}\text { (3.a) Ahömhö } & \text { hã } & \text { aibö } & \text { 1-Prãihö } & \text { wa } & \text { sõpẽtẽ, } & \text { 1-wahi } & \text { re. } \\ \text { ontem } & \text { PE } & \text { homem } & \text { 1-alto } & \text { EGO } & {\left[3^{\text {a } A B S}\right] \text { encontrar }} & \tilde{1} \text {-magro } & \text { DIM }\end{array}$

'Ontem eu encontrei um homem alto, (ele era) magrinho.'

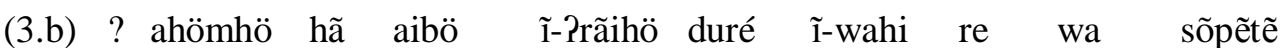
ontem PE homem ĩ-alto CONJ ĩ-magro DIM EGO $\left[3^{\mathrm{a}} \mathrm{ABS}\right]$ encontrar 'Ontem eu encontrei um homem alto e magrinho.'

$\begin{array}{cccccccc}\text { (3.c) * ahömhö hã } & \text { aibö } & \text { Prãihö duré wahi re } & \text { wa } & \text { sõpẽ } \\ \text { ontem } & \text { PE } & \text { homem alto } & \text { CONJ magro DIM EGO } & {\left[3^{\mathrm{a}} \mathrm{ABS}\right] \text { encontrar }}\end{array}$

Estes dados apontam para a idéia de que a forma simples do lexema com sentido adjetival não é livre: esta não seria uma palavra por si só e sim um componente dentro de uma palavra composta; somente a forma complexa, marcada pelo prefixo $\tilde{l}_{-}$, é livre ${ }^{2}$. A diferença entre estas duas formas está representada nos dados em (4).
(4.a) Rob?rã-sipo
wa ti-?rẽ.
fruta-estar.madura
EGO $\quad 3^{\mathrm{a}} \mathrm{ABS}$-comer

'Estou comendo uma fruta madura.'

\footnotetext{
${ }^{2}$ Veremos mais adiante que tratamos esta forma complexa como a forma nominal de um lexema verbal, usada numa oração relativa.
} 
$\begin{array}{llll}\text { (4.b) Rob?rã } & \text { í-sipo } & \text { wa } & \text { ti-?rẽ. } \\ \text { fruta } & \text { N-estar.madura } & \text { EGO } & 3^{\mathrm{a}} \mathrm{ABS} \text {-comer }\end{array}$

'Estou comendo uma fruta madura.'

Este mesmo tipo de oposição se encontra em outras línguas. Podemos observar em (5) que, segundo Van Tien Nguyen (2006, p. 97), o chinês também apresenta duas estruturas para qualificar um lexema nominal: em (a) está ilustrada a composição, envolvendo o lexema verbal cōngmíng 'ser inteligente' modificando o lexema nominal rén 'pessoa' numa palavra composta de dois radicais; em (b) a mesma qualificação é operada por um sintagma marcado pelo morfema de.
(5.a) Tā shì ȳi $\quad$ gè $\quad$ cōngmíng-rén.
ele ser um $\quad \mathrm{CL} \quad$ ser.inteligente-pessoa
'É uma pessoa inteligente.'
(5.b) Tā shì ȳì gè cōngmíng de rén.
ele ser um $\quad \mathrm{CL} \quad$ ser.inteligente $\mathrm{DE}_{1}$ pessoa
'É uma pessoa inteligente.'

Um argumento que justifica a idéia da composição em Xavante é a impossibilidade de inserir um morfema entre o nome e o lexema de qualidade: observa-se em (6) que a inserção do clítico diminutivo re só é possível entre o nome rob?rã 'fruta' e a forma prefixada por $\tilde{i}$ - do lexema com sentido adjetival $\tilde{\imath}$-sipo 'estar maduro'; ela é agramatical entre as unidades rob?rã 'fruta' e sipo 'estar maduro', por serem dois componentes de uma palavra composta.

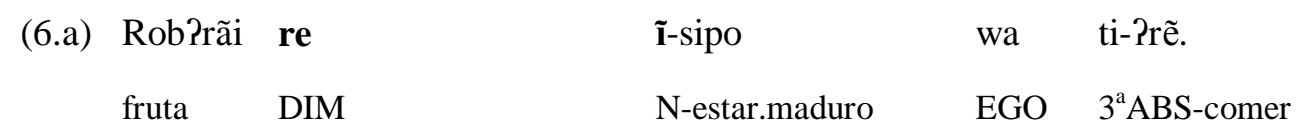

'Estou comendo uma frutinha madura.'

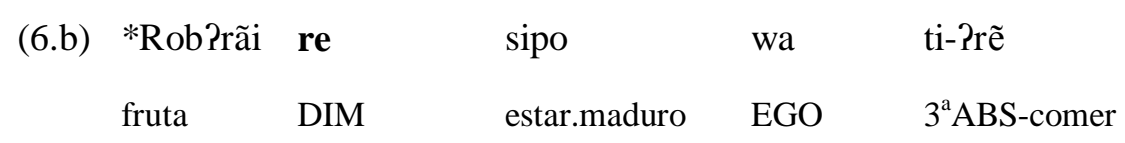

Um nome seguido de um lexema com sentido adjetival constituem, portanto, uma unidade complexa cujos elementos não podem ser separados sintaticamente; trata-se, então, de 
uma palavra composta morfo ou sintaticamente, e não de um nome seguido de um sintagma adjetival. Outros dados que levam a interpretar um nome seguido de um lexema com sentido adjetival como formando uma palavra composta estão expostos em (7): a palavra para 'anta', que tem a forma livre $u h \ddot{d} \ddot{0}$ e a forma dependente $u t \ddot{o}$, ilustradas em (a) e (b) respectivamente, só pode ser usada na forma dependente utö quando seguida por um lexema com sentido adjetival na sua forma simples, como mostram os exemplos (c) e (d); da mesma maneira, quando o lexema com sentido adjetival é usado na sua forma livre, ele só pode se combinar com a forma livre $u h o ̈ d \ddot{o, ~ c o m o ~ i n d i c a m ~ o s ~ e x e m p l o s ~(e) ~ e ~(f) . ~}$

(7.a)

$\begin{array}{llll}\text { Uhödö } & \text { misi } & \text { tãma } & \text { ti-wĩ. } \\ \text { anta } & \text { um } & 3^{\text {a }}+\text { DAT } & 3^{\text {a ABS-matar }}\end{array}$

'(A onça) matou uma anta para ele.'

(7.b) Utö-Prui-Pwa te aba mo.

anta-opôr.se-NAGT HTO caça $\quad\left[3^{\mathrm{a}} \mathrm{ABS}\right] \mathrm{ir}$

'O caçador de anta (lit. 'inimigo da anta') foi caçar.'

(7.c) Utö-za?ẽtẽ norĩ te sisa?re.

anta-ser.grande $\mathrm{COL} \quad \mathrm{HTO} \quad\left[3^{\mathrm{a}} \mathrm{ABS}\right]$ correr

'As antas grandes estão correndo.'

(7.d) * uhödö za?ẽtẽ norĩ te sisa?re

anta $\quad$ ser.grande $\quad \mathrm{COL} \quad \mathrm{HTO} \quad\left[3^{\mathrm{a}} \mathrm{ABS}\right]$ correr

(7.e) Uhödö ĩ-sa?ẽtẽ norĩ te sisa?re.

anta N-ser.grande $\quad \mathrm{COL} \quad \mathrm{HTO} \quad\left[3^{\mathrm{a}} \mathrm{ABS}\right]$ correr

'As antas grandes estão correndo.'

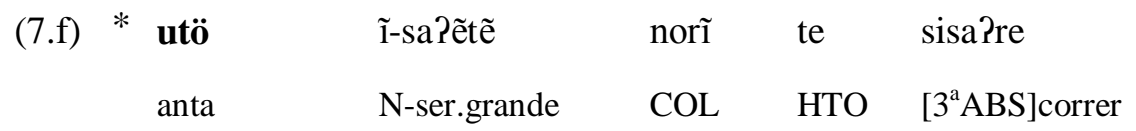

Assim, fica claro que existe uma classe de lexemas podendo qualificar um nome que não são adjetivos: na ausência de uma classe lexical de adjetivos na língua, lexemas com sentido 
adjetival modificam nomes por meio de uma composição ${ }^{3}$. Para determinar qual a categoria destes lexemas, serão examinadas a seguir suas propriedades morfológicas e sintáticas para compará-las com as propriedades morfossintáticas dos verbos e dos nomes.

\subsection{Propriedades morfossintáticas}

As propriedades morfossintáticas dos lexemas com sentido adjetival apresentadas aqui dizem respeito à flexão, à composição e às funções sintáticas.

A flexão dos lexemas com sentido adjetival é parcialmente sintética, parcialmente analítica, como mostra o quadro abaixo: índices de pessoa objeto são prefixados ao radical, enquanto este é seguido pela partícula $d i$, índice de sujeito impessoal.

Quadro 1: flexão pessoal dos lexemas com sentido adjetival (no singular)

\begin{tabular}{|l|lr|}
\hline $1^{a}$ pessoa & ĩ- & di \\
\hline $2^{a}$ pessoa não marcada & a(i)- & di \\
\hline $2^{a}$ pessoa honorífica & aa- & di \\
\hline $3^{a}$ pessoa não marcada & & di \\
\hline $3^{a}$ pessoa honorífica & ta- & di \\
\hline $3^{a}$ pessoa genérica & da- & di \\
\hline
\end{tabular}

A morfologia dos lexemas com sentido adjetival sugere que estes lexemas são verbos usados numa construção impessoal: o exemplo (8.a) mostra como o índice di representa um sujeito impessoal, por oposição ao sujeito dawara 'corrida', marcado pelo índice de sujeito heterofórico $t e^{4}$ em (8.b). Ou seja, o lexema com sentido adjetival wasutu 'estar cansado' pode ser analisado como um verbo transitivo com sentido dinâmico 'cansar', cuja interpretação estativa obtem-se com um sujeito impessoal. Em outras palavras, 'ele está cansado' se diz literalmente algo como 'o está cansando'. Neste caso, trata-se em (8) de um mesmo lexema usado em duas construções diferentes; nossa hipótese, porém, é que existem dois lexemas distintos - visto que não são todos os verbos transitivos que podem entrar numa construção impessoal - e por isso a glose é 'estar.cansado' em (8.a) e 'cansar' em (8.b).

\section{(8.a) Õhã wasutu di. \\ PR. $3^{\mathrm{a}} \quad\left[3^{\mathrm{a}} \mathrm{ABS}\right]$ estar.cansado IMP}

'Ele está cansado.'

\footnotetext{
${ }^{3}$ Existem certamente restrições semânticas, ainda por serem investigadas.

${ }^{4}$ Ver 2.1. e a nota 10.
} 


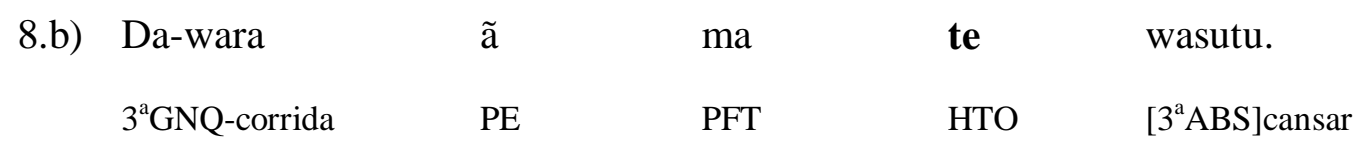

'A corrida o cansou.'

Em todo caso, veremos mais adiante que a marca 'zero' na terceira pessoa, ilustrada em (8) com o lexema wasutu 'estar cansado', prova que os índices pessoais prefixados ao radical dos lexemas com sentido adjetival são verbais. Além disso, o morfema di não se emprega com nomes, mas é obrigatório com verbos depois da negação. Ou seja, a morfologia flexional dos lexemas com sentido adjetival é uma morfologia verbal.

Paralelamente às formas marcadas pelo índice de sujeito impessoal di, os lexemas com sentido adjetival também aparecem marcados pelo prefixo $\tilde{l}$-: este morfema flexional indica, como veremos a seguir, a forma nominal de um lexema verbal, permitindo a este acessar as funções nominais (complemento e predicado). Os exemplos abaixo mostram que o lexema com sentido adjetival, mesmo na forma nominal, continua recebendo as marcas de pessoa do seu argumento.
(9.a) Ahã
ĩ-ai-prã.
PR. $2^{\mathrm{a}}$
N-2 $2^{\mathrm{a}}$ ABS-ser.falso

'Você é falso.'
(9.b) Uburé ĩi-ma ĩ-da-wẽ.
todos $\quad 1^{a}$ SG-DAT N-3 $\quad$ anQ.ABS-ser.bom

'Gosto de todos.'

Os lexemas com sentido adjetival podem participar da construção de uma palavra composta no sentido de composé au sens fort definido por Mel'čuk (1997, p. 87-89) como segue:

Nous distinguerons composés au sens fort, ou composés, et composés au sens faible, ou composés ${ }_{2}$. [...] Les lexèmes composés ${ }_{1}$ sont LIBREMENT FORMÉS par le locuteur dans le processus de parole [...], sont de « vrais » composés, des composés synchroniques, tandis que les composés ${ }_{2}$ ne sont que des composés diachroniques. [...] Un lexème composé ${ }_{1}$ (= composé au sens fort) ne doit pas apparaître dans un dictionnaire : il est tout à fait fabricable par règle, sur la base des racines emmagasinées dans la langue, et ne manifeste aucune phraséologisation. ${ }^{5}$

\footnotetext{
5 'Faremos a distinção entre lexemas compostos no sentido forte, ou compostos $_{1}$, e lexemas compostos no sentido fraco, ou $\operatorname{compostos}_{2}$. [...] Os lexemas compostos 1 são FORMADOS LIVREMENTE pelo locutor durante o processo da fala [...], são 'verdadeiros' lexemas compostos, compostos sincrônicos, enquanto os lexemas $\operatorname{compostos}_{2}$ são
} 
Assim, os lexemas com sentido adjetival podem se combinar com lexemas tanto nominais quanto verbais para formar de maneira produtiva palavras compostas ${ }^{6}$ com sentido composicional: nos exemplos em (10), o lexema prédub 'ser maduro' se combina com o lexema nominal aibö 'homem' em (a) e com o lexema verbal zada?öbö 'responder' em (b).

$$
\begin{array}{llll}
\text { (10.a) } & \text { Aibö-prédu } & \text { wa } & \text { sõpẽtẽ. } \\
& \text { homem-ser.maduro } & \text { EGO } & {\left[3^{\mathrm{a}} \mathrm{ABS}\right] \text { encontrar }}
\end{array}
$$

'Encontrei um homem maduro.'

$\begin{array}{llllllll}\text { (10.b) } & \text { Ãne } & \text { za } & \text { wa-Prada } & \text { wa-te } & \text { Pre } & \text { da-zada?öbö-prédub } & \text { zaPra. } \\ & \text { assim } & \text { PROSP } & 1^{\text {a } P L-a v o ́} & 1^{a} \text { PL.ERG-AUX } & \text { PVB } & \begin{array}{l}3^{\mathrm{a}} \text { H.ABS-responder- } \\ \text { ser.maduro }\end{array} & \text { PL }\end{array}$

'É assim que vamos responder à nossa avó (como pessoas) maduras.'

Os lexemas com sentido adjetival não se encontram somente neste tipo de palavra composta, cujo núcleo é o nome ou o verbo qualificado ; eles também podem servir de núcleo para uma palavra composta, como no caso da incorporação, ilustrada nos exemplos abaixo. O lexema com sentido adjetival pode incorporar o seu argumento, se este for um nome divalente: em (11), o lexema com sentido adjetival pa 'ser comprido' incorpora o seu argumento, o nome divalente paihi 'braço', cujo argumento de segunda pessoa se torna sujeito da oração. Neste tipo de incorporação, o lexema com sentido adjetival é usado na sua forma nominal, mencionada em 1.2.1.

\author{
(11.a) Ai-paihi ĩ-pa. \\ $2^{\mathrm{a}}$-braço $\quad \mathrm{N}\left[3^{\mathrm{a}} \mathrm{ABS}\right]$ ser.comprido \\ 'Teu braço é comprido.'
}

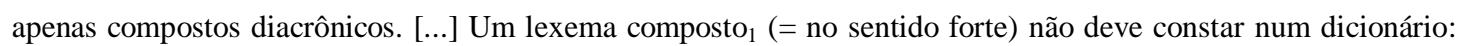
ele é perfeitamente fabricável por regra, com base nas raízes estocadas na língua, e não manifesta nenhum sinal de fraseologia.' (Tradução nossa.)

${ }^{6}$ É difícil dizer se a composição é morfológica ou sintática. Um argumento a favor deste tipo de composição ser um processo submetido a regras morfológicas envolve verbos como mreme 'falar', que perdem a sílaba final na segunda pessoa: quando seguidos por um lexema com sentido adjetival, a apócope atinge a última sílaba do radical complexo, como mostram os exemplos a seguir com o verbo mreme 'falar', o lexema com sentido adjetival su?u 'ser rápido' e o verbo composto mreme-su?u 'falar rápido'.
\end{abstract}
(a) $\mathrm{E}$ te $\mathrm{za}$ ai-mre ?
PI HTO PROSP $2^{\mathrm{a} A B S-f a l a r}$
Você vai falar?

(b) $\mathrm{E}$ te za ai-mreme-su ?

PI HTO PROSP $2^{\mathrm{a}}$ ABS-falar-ser.rápido

Você vai falar alto? 
(11.b) Ahã ĩ-ai-paihi-pa.

PR.2 $2^{\mathrm{a}} \quad \mathrm{N}-2^{\mathrm{a}} \mathrm{ABS}$-braço-ser.comprido

'Você é comprido de braço.'

Além da incorporação do argumento, a incorporação também pode ser classificatória, involvendo, nesse caso, nomes não contaveis (sendo facultativa com nomes contaveis): os exemplos em (12) ilustram a incorporação pelo lexema com sentido adjetival tete 'ser duro' do nome contável zöp 'grão', que determina a classe semântica do argumento asaro 'arroz' em (b). Neste caso, o lexema com sentido adjetival, núcleo da palavra composta, está exercendo a função de predicado, acompanhado do índice de sujeito impessoal di, discutido no parágrafo anterior.

$\begin{array}{llll}\text { (12.a) } & \text { Uwai?rewawẽ zahadu tete } & \text { di. } \\ \text { abacate ainda } \quad\left[3^{\mathrm{a} A B S}\right] \text { estar.duro } & \text { IMP } \\ \text { 'O abacate ainda está verde.' } & \\ \text { (12.b) } & \text { Asaro zöp-tete } & \text { di. } \\ & \text { arroz } \quad\left[3^{\mathrm{a} A B S}\right] \text { grão-estar.duro } & \text { IMP } \\ & \text { 'O arroz está duro/verde.' }\end{array}$

Em suma, comparando a morfologia dos lexemas de sentido adjetival com a morfologia dos verbos, apresentada em 2., fica claro que eles apresentam uma morfologia verbal. Eles têm como particularidade o uso - na função predicativa - de uma construção impessoal marcada pelo índice de sujeito impessoal di. Vejamos a seguir os papéis sintáticos desempenhados por estes lexemas.

Do ponto de vista sintático, os lexemas com sentido adjetival se caracterizam pelo acesso às funções de predicado e complemento, apresentadas a seguir.

Os lexemas com sentido adjetival têm acesso à função de predicado de duas maneiras: numa construção impessoal com o índice $d i$, e como núcleo de um sintagma equivalente a um sintagma nominal com o prefixo da forma nominal $\tilde{\imath}$-. Estas duas construções estão ilustradas respectivamente em (13.a) e (13.b) com o lexema de sentido adjetival pa 'ser comprido,7.

\footnotetext{
${ }^{7}$ A tradução dos exemplos é aproximativa, pois a diferença semântica entre as duas construções ainda merece ser estudada: uma hipótese a ser aprofundada é que a construção em (a) atribui uma propriedade ao sujeito (leitura intencional) enquanto que a predicação em (b) o identifica com um indivíduo (leitura extencional).
} 
$\begin{array}{llllll}\text { (13.a) Âhã } & \text { wede } & \text { hã } & \text { pa } & \text { di. } \\ & \text { DEM } & \text { pau } & \text { PE } & {\left[3^{\mathrm{a}} \mathrm{ABS}\right] \text { ser.comprido }} & \text { IMP }\end{array}$

'Esse pau está comprido.'

(13.b) Ãhã wede hã î-pa.

DEM pau PE N[3 $\left.3^{\mathrm{a} A B S}\right]$ ser.comprido

'Esse pau é comprido.'

Observa-se em (14) que as marcas de tempo-aspecto-modo usadas com os lexemas de sentido adjetival em função de predicado são as mesmas quando o predicado é verbal: a partícula de prospectivo za usada em (a), assim como a partícula de modo irrealis éré em (b) podem ser observadas a seguir em (17) com o verbo ñono 'dormir'.
(14.a) E ai-ma mram
di $\quad$ za $\quad$ ?
PI $\quad 2^{\mathrm{a}}$-DAT $\left[3^{\mathrm{a}} \mathrm{ABS}\right]$ estar.faminto
IMP PROSP

'Você vai ficar com fome?'

$\begin{array}{lllll}\text { E } & \text { éré } & \text { ai-ma } & \text { mram } & \text { di } \\ \text { PI } & \text { IRR } & 2^{\text {a }} \text {-DAT } & {\left[3^{\text {a }} \text { ABS }\right] \text { estar.faminto }} & \text { IMP }\end{array}$

'Você estava com fome?'

Quando usado na forma nominal, o lexema com sentido adjetival tem acesso às funções de complemento: ele funciona como o núcleo de um constituinte que é equivalente, do ponto de vista de suas funções sintáticas, a um sintagma nominal. (Trata-se de uma oração relativa do tipo comumente designado em inglês como head-internal ${ }^{8}$.) No exemplo (15), a palavra isiptete - forma nominal do lexema com sentido adjetival siptete 'ser forte' - é o núcleo de um constituinte que funciona como um sintagma nominal em função de adjunto, marcado pela posposição instrumental na. Observa-se que o nome qualificado pela oração relativa, dawedezé 'remédio', pode ser omitido.

\footnotetext{
${ }^{8}$ Este tipo de oração relativa parece ser comum nas línguas macro-jê; para exemplos em mẽbengokre e em karajá, ver respectivamente Salanova (2011) e Ribeiro (2006).
} 
[Dawedezé î-siptete ] na te wa-wede za?ra mono õ di remédio $\quad \mathrm{N}\left[3^{\mathrm{a}} \mathrm{ABS}\right] \mathrm{ser}$.forte INSTR $\quad\left[3^{\mathrm{a}} \mathrm{ERG}\right] \mathrm{AUX} \quad 1^{\mathrm{a}} \mathrm{PL} . \mathrm{ABS}$-tratar $\quad$ PL ITR NEG EXPL

'Não estão nos tratando com remédios suficientemente bons,'

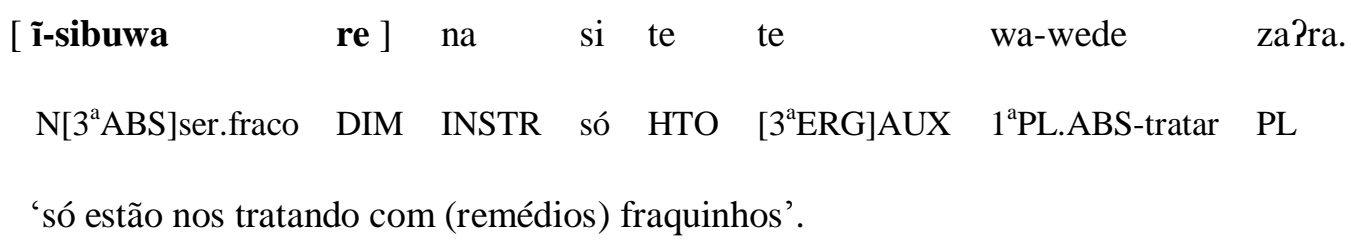

Termina aqui o panorama das propriedades morfossintáticas dos lexemas com sentido adjetival, onde foram apontadas semelhanças com as propriedades formais dos verbos. Estas são o objeto dos próximos parágrafos.

\section{Lexemas verbais}

Apresentamos aqui as características morfossintáticas dos lexemas verbais em comparação com as propriedades dos lexemas de sentido adjetival: a flexão é abordada em 2.1., a composição em 2.2. e as funções sintáticas são tratadas em 2.3.

\subsection{Flexão}

As categorias da flexão verbal examinadas aqui são as de pessoa, modalidade, finitude e polaridade. Os morfemas incluídos aqui podem ser afixos, clíticos ou partículas: sejam eles fonologicamente livres ou dependentes, são considerados como parte da flexão verbal por entrarem numa série de oposições constituindo um paradigma de valores para uma mesma categoria flexional.

A categoria da pessoa na flexão verbal é marcada por várias séries de morfemas: uma série de prefixos ergativa ${ }^{9}$, uma série de prefixos absolutiva e uma série de clíticos nominativos. Os morfemas que nos interessam aqui são os prefixos da série absolutiva no singular ${ }^{10}$, apresentados no quadro 2. ( $\mathrm{O}$ condicionamento dos alomorfes pode ser aspectual ou morfológico.)

\footnotetext{
${ }^{9}$ Esta série opõe somente a segunda pessoa, marcada pelo prefixo $\tilde{\imath}$-, a todas as outras. Para não sobrecarregar as glosas, não indicaremos o valor 'não segunda pessoa ergativa' correspondente à ausência de marca fonológica quando o sujeito de um verbo transitivo for de primeira ou terceira pessoa.

${ }^{10}$ A única expressão nos prefixos de pessoa da categoria do número se vê na primeira pessoa: assim, o prefixo absolutivo de primeira pessoa é $\tilde{\imath} l^{-}$no singular e $w a$ - no plural. Nas outras pessoas, o número é marcado por partículas pospostas ao verbo.
} 
Quadro 2: série absolutiva de prefixos pessoais verbais

\begin{tabular}{|l|l|}
\hline $1^{a}$ pessoa & ĩ- $\sim \emptyset$ \\
\hline $2^{a}$ pessoa não marcada & a(i)- \\
\hline $2^{a}$ pessoa honorífica & aa- \\
\hline $3^{a}$ pessoa não marcada & ti- $\sim \emptyset$ \\
\hline $3^{a}$ pessoa honorífica & ta- $\sim$ da- \\
\hline $3^{a}$ pessoa genérica & da- \\
\hline
\end{tabular}

Nota-se que a única diferença com os prefixos nominais (apresentados em 3.2.) se vê na marca 'zero' de terceira pessoa característica de uma classe morfológica de verbos, representada nos exemplos seguintes. O morfema sem conteúdo fonológico indica a terceira pessoa sujeito do verbo intransitivo ñono 'dormir' em (16.a) e objeto do verbo transitivo sa?wa 'jogar' em (16.b).
(16.a) $\mathrm{Te}$ ñono.
HTO $\quad\left[3^{\mathrm{a}} \mathrm{ABS}\right]$ dormir

'Ele está dormindo.'

$\begin{array}{llll}\text { (16.b) } & \text { Ĩhöiwarobo } & \text { ma } & \text { sa?wa. } \\ \text { papel } & \text { PFT } & {\left[3^{\mathrm{a} A B S] j o g a r}\right.}\end{array}$

'Ele jogou o papel.'

Observa-se que o uso das marcas nominativas do sujeito - os clíticos heterofórico te e egofórico $w a^{11}$, que aparecem respectivamente em (16.a) e (17) - constitui a única diferença, em termos de flexão pessoal, entre os verbos e os lexemas com sentido adjetival.

Em termos de modalidade, pode-se ilustrar a flexão verbal com as partículas de prospectivo za e de irrealis éré, como mostram respectivamente os exemplos (17.a) e (17.b). Lembramos que são os mesmos morfemas que se combinam com os lexemas de sentido adjetival exercendo a função de predicado.
(17.a) Wa za ñono.

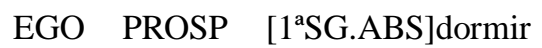

'Eu vou dormir.'

\footnotetext{
${ }^{11}$ Seguimos aqui a terminologia sugerida por Tournadre (1994) para uma marcação que distingue a primeira pessoa de todas as outras.
} 
(17.b) Wa éré ñono.

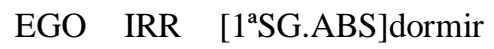

'Eu dormi.'

A flexão verbal também inclui a categoria da finitude: veremos em 2.3. que na sua forma não finita, o verbo pode ser o núcleo de um constituinte equivalente - do ponto de vista do seu papel sintático - a um sintagma nominal. Indicaremos aqui apenas que esta forma é flexional $^{12}$ e que ele é marcada pelo prefixo $\tilde{i}$. É importante ressaltar também que, mesmo na sua forma nominal, o verbo continua expressando a pessoa, como mostra o Quadro 3. Assim, no exemplo (18), a forma nominal do verbo höimana 'viver' na primeira pessoa plural é marcada pelos prefixos $\tilde{i}$ - e $w a-$.

\section{Quadro 3: prefixos pessoais dos verbos na forma nominal}

\begin{tabular}{|l|l|}
\hline $1^{a}$ pessoa singular & $\tilde{\mathbf{1}}-$ \\
\hline $1^{a}$ pessoa plural & $\tilde{\mathbf{i}}$-wa- \\
\hline $2^{\text {a }}$ pessoa não marcada & $\tilde{\mathbf{i}}-\mathrm{a}(\mathrm{i})-$ \\
\hline $2^{\mathrm{a}}$ pessoa honorífica & $\tilde{\mathbf{i}}$-aa- \\
\hline $3^{\mathrm{a}}$ pessoa não marcada & $\tilde{\mathbf{i}}-$ \\
\hline $3^{\mathrm{a}}$ pessoa genérica & $\tilde{\mathbf{i}}$-da- \\
\hline
\end{tabular}

(18) Pre î-wa-höimana za?ra mono

PVB N-1 $\quad 1^{\mathrm{a} P L}$.ABS-viver PL ITR

'o fato de estarmos vivendo'

Para terminar esta apresentação das propriedades flexionais dos verbos, indicaremos que a negação do verbo - quando este é o predicado numa oração independente - é sempre acompanhada pela partícula $d i^{13}$, como mostram os exemplos em (19): a forma negativa do

\footnotetext{
${ }^{12}$ Sobre a mudança de categorias sintáticas operada por flexão, ver Haspelmath (1996).

${ }^{13}$ Consideramos aqui o morfema di como um índice expletivo, pois a negação não pode ser analisada como uma construção impessoal; é claro, porém, que o índice expletivo e o índice de sujeito impessoal são hoje dois morfemas homônimos que têm uma origem comum.
} 
verbo usado em (a) aparece em (b) não só com a marca de negação õ como também o morfema di; o dado em (c) mostra que, na ausência desta partícula, a negação se torna agramatical.
(19.a) Wa za wara.
EGO PROSP $\quad\left[1^{\mathrm{a} S G}\right.$ ABS $]$ correr

'Vou correr.'

(19.b) ̃̃̂-wara

$1^{\mathrm{a} S G}$.ABS-correr

'Não vou correr.'
(19.c) * $*$ 1ิ-wara
õ za.
$1^{\text {a } S G . A B S-c o r r e r ~}$
NEG PROSP

\subsection{Composição}

Os lexemas verbais podem se combinar com um lexema nominal para formar um verbo composto de duas maneiras: por incorporação do argumento - ilustrada nos exemplos (20) e (21) com verbos respectivamente intransitivo e transitivo - ou por incorporação classificatória representada em (22).

$\begin{array}{lllll}\text { (20.a) } & \text { Ö } & \text { te } & \text { za } & \text { ti-Pré. } \\ & \text { água } & \text { HTO } & \text { PROSP } & 3^{\mathrm{a}} \mathrm{ABS} \text {-secar }\end{array}$

'A água vai secar.'
(20.b) $\mathrm{Te}$
za ti-ö-?ré.
HTO PROSP $3^{\mathrm{a} A B S}$-água-secar

'Vai acabar a água.'
(21.a) E $\tilde{11}-\mathbf{z a}$ te za ĩ-ta ?
PI $\quad 1^{\text {a SG-coxa }}$ HTO PROSP $2^{\mathrm{a} E R G\left[3^{\mathrm{a}} \mathrm{ABS}\right] \text { arrancar }}$
'Você vai arrancar a minha coxa?'
(21.b) E te za ĩ-za-ta ?
PI HTO PROSP $2{ }^{\mathrm{a}} \mathrm{ERG}+1^{\mathrm{a}} \mathrm{SG}$.ABS-coxa-arrancar

'Você vai me arrancar a coxa?' 


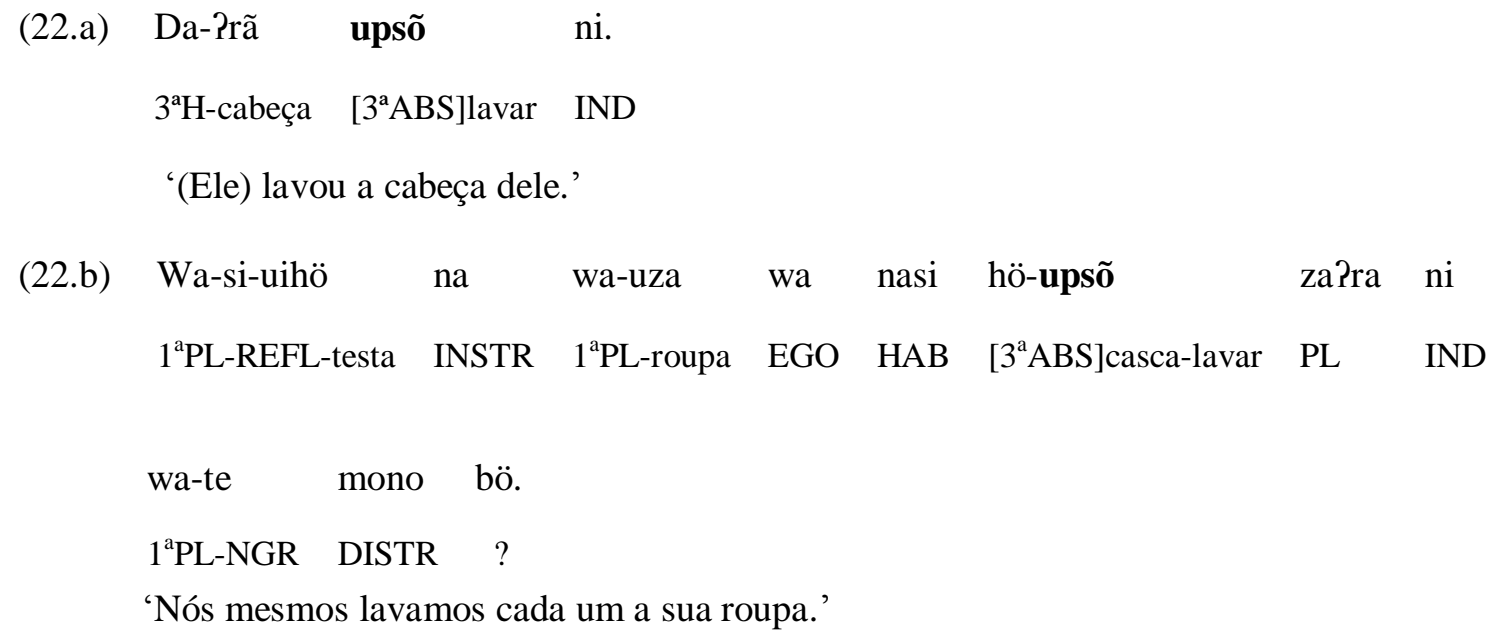

\subsection{Funções sintáticas}

Na sua forma finita, o verbo exerce a função sintática de predicado numa oração independente: em (23), é o caso do verbo te ñono 'ele dorme'.

$\begin{array}{lllllll}\text { (23) Tawamhã, } & \text { sô } & \text { morĩ } & \text { wamhã, } & \text { hu } & \text { te } & \text { ñono. } \\ \text { então } & \text { PVB } & {\left[3^{\mathrm{a}} \mathrm{ABS}\right] \text { ir }} & \text { quando } & \text { onça } & \text { HTO } & {\left[3^{\mathrm{a}} \mathrm{ABS}\right] \text { dormir }}\end{array}$

'Então, quando eles foram atrás dele, a onça estava dormindo.'

Na sua forma não finita, marcada pelo prefixo $\tilde{l}$-, o verbo é o núcleo de um constituinte que tem acesso a todas as funções de um sintagma nominal, mas que tem a estrutura interna de uma oração. Em (24), (25) e (26) um tal constituinte ocupa as posições de complemento sujeito, objeto e oblíquo respectivamente. O exemplo (27) mostra que um tal constituinte também pode exercer a função de predicado, da mesma forma que um sintagma nominal numa predicação inclusiva.
(24) [ Ĩsépu wa-te
ĩ-a-zéptö ]
te oto Pre nomro.
doente $1^{\mathrm{e} P L . E R G-A U X}$
$\mathrm{N}\left[3^{\mathrm{e}} \mathrm{ABS}\right] \mathrm{COL}-\mathrm{curar}$
HTO
INC PVB $\left[3^{\mathrm{e}} \mathrm{ABS}\right] \mathrm{andar}$
'Os doentes que nós curamos estão andando agora.'
(25) [ Mimi da-te
İ-ubumro ] wa wa-te waibu.
lenha $\quad 3^{\mathrm{e}}$ GNQ.ERG-AUX $\quad \mathrm{N}\left[3^{\mathrm{e}} \mathrm{ABS}\right] \mathrm{juntar} \quad$ EGO $\quad 1^{\mathrm{e}}$ PL.ERG-AUX $\quad\left[3^{\mathrm{e}} \mathrm{ABS}\right]$ pegar
'Nós pegávamos a lenha que (os homens) juntavam.' 
$(26)$

$$
\begin{array}{llllllll}
\text { Ãmem } & \text { hã } & 25 & \text { na } & \text { ma } & \text { wa-ãma } & \text { ti-wahu } & \text { oto } \\
\text { aqui } & \text { PE } & 25 & \text { INSTR } & \text { PFT } & 1^{\mathrm{a}} \text { PL-PVB } & 3^{\mathrm{a}} \text { ABS-completar.um.ano } & \text { INC }
\end{array}
$$

$\begin{array}{lllllll}\text { [ãme } & \text { Pre } & \text { I-wa-höimana } & \text { zaPra } & \text { mono ] } & \text { na } & \text { hã. } \\ \text { aqui } & \text { PVB } & \text { N-1 }{ }^{\mathrm{a}} \text { PL.ABS-viver } & \text { PL } & \text { ITR } & \text { INSTR } & \text { PE }\end{array}$

'Moramos aqui há 25 anos. (lit. "Anuou por 25 vezes pelo nosso viver aqui.”)'

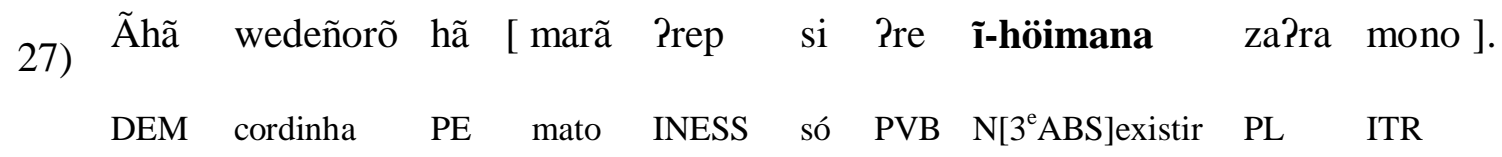

'Estas cordinhas são (das) que ficam só no mato.'

Em resumo, os lexemas com sentido adjetival compartilham uma série de propriedades morfossintáticas com os lexemas verbais: a marcação de pessoa é idêntica à série de prefixos pessoais verbais; as mesmas partículas modais são usadas na predicação; o mesmo prefixo $\tilde{l}$ indica que o lexema tem uma forma não finita usada como núcleo de um constituinte sintaticamente equivalente a um sintagma nominal; o mesmo marcador $d i$, que aparece na negação verbal, é usado para marcar um sujeito impessoal numa das construções usadas para a predicação dos lexemas com sentido adjetival. Além disso, estes últimos podem formar uma palavra composta, incorporando um lexema nominal numa incorporação argumental ou classificatória. Por fim, os lexemas com sentido adjetival têm, assim como os verbos e com as mesmas particularidades morfológicas, acesso às funções de predicado e complemento.

Em comparação, as propriedades morfossintáticas dos lexemas nominais são outras, como veremos nos parágrafos seguintes.

\section{Lexemas nominais}

Antes de serem apresentadas a flexão e a composição dos nomes em 3.1. e 3.2. respectivamente, serão feitas em 3.1. algumas observações sobre as classes morfológicas nominais. Em seguida serão abordados os papéis sintáticos desempenhados pelos nomes.

\subsection{Classes morfológicas}

Existem duas classes morfológicas de lexemas nominais, ilustrada nos exemplos a seguir: a primeira - invariável - é constituída por nomes monovalentes (ou 'alienáveis'); a 
segunda - flexionável - por nomes divalentes (ou 'inalienáveis') ${ }^{14}$. Os nomes monovalentes só possuem um argumento, que aparece sob a forma de um sintagma nominal sujeito numa predicação inclusiva. Para introduzir um novo participante como dependente sintático do nome monovalente, é necessário associá-los por um nome genérico relacional. Assim, o participante com papel de 'possuidor' do nome monovalente wapsã 'cachorro' expresso pelo nome aibö 'homem' em (28) é introduzido como complemento do nome genérico relacional te 'coisa de'. Já os nomes divalentes têm um argumento interno - além daquele (externo) que aparece como sujeito numa predicação - cuja expressão é obrigatória. Em (29) observa-se que a expressão do argumento interno de um nome divalente pode ser sintática - o sintagma nominal wapsã ‘cachorro' em (a) - ou morfológica - o prefixo $\tilde{i}$ - em (b).
(28) aibö te wapsã
homem NGR cachorro
'cachorro do homem'
(29.a) wapsã Prã
cachorro cabeça
'cabeça do cachorro'
(29.b) $\quad \tilde{\mathbf{i}}-$ Prã
$3^{\mathrm{a}}$-cabeça
'cabeça dele'

Os nomes divalentes podem ser derivados de nomes monovalentes ou de verbos. No primeiro caso, ilustrado em (30), a derivação é marcada pelo prefixo ñiP-: o nome divalente ñipi?õ 'mulher de' - cujo argumento interno é expresso pelo sintagma nominal warazu 'homem branco' em (a) e pelo prefixo de primeira pessoa plural wa- em (b) - é derivado do nome

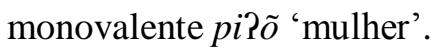
(30.a) warazu
ñi-pi?õ
homem.branco APL.N-mulher
'mulher do homem branco'

\footnotetext{
${ }^{14}$ Adotamos aqui a análise de Queixalós (2005) dos nomes em Katukina, que nos parece válida também para os nomes em Xavante.
} 
(30.b) wa-ñi-pi?õ

1'PL-APL.N-mulher

'nossas mulheres'

Em (31) está ilustrada a derivação de um nome divalente a partir de um lexema verbal pelo prefixo ñimi- $\sim$ simi-. $\mathrm{O}$ argumento interno do nome divalente ñimiromhuri simiromhuri 'trabalho de' - derivado do lexema verbal romhuri 'trabalhar' - aparece sob a forma do sintagma nominal pi?õ 'mulher' em (a) e sob o prefixo de terceira pessoa $\tilde{\imath}$ - em (b).
$\begin{array}{lll}\text { (31.a) } & \text { pi̊̃̃ } & \text { ñimi-romhuri } \\ & \text { mulher } & \text { NMZ-trabalhar }\end{array}$
'trabalho de mulher'
(31.b) ĩ-simi-romhuri
$3^{\text {a }}$-NMZ-trabalhar
'seu trabalho'

A construção de nomes divalentes por derivação prefixal foi mencionada aqui para apoiar uma hipótese diacrônica, proposta em 4. Antes disso, o parágrafo seguinte - que apresenta a flexão dos nomes divalentes - mostra que esta é diferente da flexão dos lexemas com sentido adjetival.

\subsection{Flexão}

A flexão dos nomes divalentes, parcialmente ${ }^{15}$ representada no Quadro 4, mostra que a série dos prefixos de pessoa nominais (ou 'prefixos possessivos') se distingue da série dos prefixos de pessoa verbais principalmente pela marcação da terceira pessoa, sendo $\tilde{\imath}$ - no caso dos nomes e $t i$ - ou 'zero' no caso dos verbos.

\footnotetext{
${ }^{15}$ A observação feita na nota 9 sobre a flexão verbal também é aplicável aqui no caso dos nomes: a categoria do número - que não é pertinente neste contexto - é expressa por partículas pós-verbais, com exceção da primeira pessoa plural, marcada pelo prefixo $\mathrm{wa}$.
} 


\section{Quadro 4: flexão dos nomes divalentes}

\begin{tabular}{|l|l|}
\hline $1^{a}$ pessoa & ĩ̃- \\
\hline $2^{a}$ pessoa não marcada & a(i)- \\
\hline $2^{a}$ pessoa honorífica & aa- \\
\hline $3^{\text {a }}$ pessoa não marcada & í- \\
\hline $3^{\text {a }}$ pessoa honorífica & ta- \\
\hline $3^{\text {a }}$ pessoa co-referente & ti- \\
\hline $3^{\text {a }}$ pessoa genérica & da- \\
\hline
\end{tabular}

Assim, o radical verbal -mreme aparece na terceira pessoa em (32.a) sem marca fonológica, enquanto o radical nominal da mesma forma em (32.b) é prefixado pelo morfema de terceira pessoa $\tilde{l}$ -

(32.a) Ãne te mreme.

assi $\quad \mathrm{HT} \quad\left[3^{\mathrm{a}} \mathrm{ABS}\right] \mathrm{fala}$

$\mathrm{m} \quad \mathrm{O} \quad \mathrm{r}$

Ele falou assim.

(32.b) Ãhãta ĩ-mreme wawã hã aimawi.

$\begin{array}{clll}\text { DEM } \quad 3^{\text {a }} \text {-fala } & \text { som } \quad \begin{array}{l}\text { P } \\ \end{array} \\ & \text { E } \quad \mathrm{e}\end{array}$

Lá o som da fala (do povo) é diferente.

\subsection{Composição}

Ao contrário dos verbos, os nomes não incorporam um argumento; eles podem apenas se combinar com um lexema de sentido adjetival, sendo o núcleo numa composição atributiva. Nos seguintes exemplos, as qualidades 'ser falso' e 'ser antigo' são atribuídas aos nomes $a$ ?é 'colar' e ñitobrui 'inimigo' pelos lexemas prã e Prada respectivamente dentro de uma palavra composta. 
(33.a) a?é-prã

colar-ser.falso

'colar falso'

(33.b) ก̃i-nitobrui-?rada

$1^{\text {a } S G-i n i m i g o-s e r . a n t i g o ~}$

'meu antigo inimigo'

\subsection{Funções sintáticas}

Os lexemas nominais têm acesso à função de predicado sem que seja necessário o uso de uma cópula, mesmo que a propriedade atribuída pelo sintagma nominal predicado seja determinada como posterior ou anterior a um ponto de referência. Para ser marcada como posterior, o sintagma nominal é seguido por um morfema gramatical ${ }^{16}$, o projetivo $d a$, ilustrado em (34.b); a anterioridade, por sua vez, é expressa pela composição do nome com o lexema de sentido adjetival Prada 'ser antigo', como mostra o exemplo (34.c).
(34.a) Ãhã
aibö
utö-Prui-?wa.
DEM
homem
anta-opôr.se-NAGT

'Esse homem é caçador de anta.'

$\begin{array}{llllll}\text { (34.b) } & \text { Ãhã } & \text { aibö } & \text { utö-Prui-Pwa } & \text { da } & \text { hã. } \\ & \text { DEM } & \text { homem } & \text { anta-opôr.se-NAGT } & \text { PRO } & \text { PE }\end{array}$

'Esse homem vai ser caçador de anta. (lit. 'Esse homem é um futuro caçador de anta.')'

$\begin{array}{llll}\text { (34.c) } & \text { Ãhã } & \text { aibö } & \text { utö-Prui-Pwa-Prada. } \\ & \text { DEM } & \text { homem } & \text { anta-opôr.se-NAGT-ser.antigo }\end{array}$

'Esse homem foi caçador de anta.'

Nota-se que a expressão da posterioridade e anterioridade é diferente com um predicado verbal: lembramos que a interpretação temporal de uma predicação verbal obtém-se com partículas modais.

\footnotetext{
${ }^{16}$ Que também serve para marcar o sintagma nominal em função de complemento.
} 
Outra função sintática acessível aos nomes é a função de complemento - seja este a expressão de um argumento previsto pela valência do lexema verbal ou um adjunto. No exemplo a seguir, os sintagmas nominais assinalados em negrito funcionam como complemento sujeito, objeto e oblíquo.

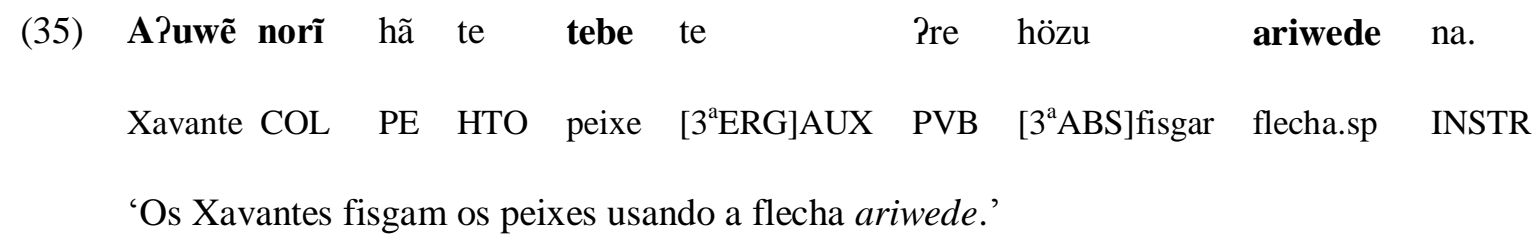

Vale ressaltar que, sendo o núcleo de um sintagma em função de complemento, os nomes não são marcados por um morfema específico para esta função, ao contrário dos verbos, que necessitam o prefixo da forma nominal $\tilde{l}$ -

Fica claro, portanto, que os lexemas com sentido adjetival não são nominais e constituem uma subclasse dentro da categoria dos lexemas verbais. Para concluir, algumas observações são apresentadas nos seguintes parágrafos para sugerir uma hipótese diacrônica.

\section{Hipótese diacrônica}

Como veremos com os dados a seguir, os lexemas com sentido adjetival - apesar de serem verbais numa análise sincrônica - podem ter uma origem nominal.

Uma primeira observação diz respeito à partícula di: o exemplo em (36.a), encontrado em McLeod e Mitchell (2003, p. 74), mostra este morfema combinado ao sintagma nominal aibö 'homem' como sendo uma cópula existencial. Talvez ainda seja o caso em certos dialetos, mas na região onde nossos dados foram recolhidos, uma predicação existencial se dá como em (36.b), com outro morfema gramatical. Ou seja, os lexemas com sentido adjetival - atualmente verbos - podem ter sido nomes usados numa predicação existencial com a cópula di. Estes nomes poderiam ter sido reanalisados em verbos consequentemente à perda do sentido existencial do morfema $\mathrm{di}$.

$\begin{array}{lll}\text { (36.a) } & \text { Aibö di. } & \\ & \text { homem EXIST } \\ & \text { 'Há homens.' } & \\ & & \\ \text { (36.b) } & \text { Aibö iré hã } & \\ & \text { homem EXIST PE } \\ & \text { 'Há homens.' }\end{array}$


Além disto, prefixos derivacionais nominais encontram-se 'fossilizados' dentro do radical de certos lexemas com sentido adjetival: rastros do aplicativo nominal $\tilde{n} i P-$, morfema aumentador de valência dos nomes monovalentes, e do prefixo de derivação deverbal ñimisimi-, ambos construindo nomes divalentes, estão ilustrados respectivamente em (37.a) e (37.b).

\author{
(37.a) Wahã ก̃i-ñiptede. \\ PR. $1^{\text {a }} \quad \mathrm{N}+1^{\text {a }} \mathrm{SG} . \mathrm{ABS}-\mathrm{ser}$. forte
}

'Eu sou forte.'

$\begin{array}{llll}\text { (37.b) Ai̊uté } & \text { hã } & \text { simiza?rese } & \text { di. } \\ \text { criança } & \text { PE } & {\left[3^{\text {a }} \mathrm{ABS}\right] \text { ser.esperto }} & \text { IMP } \\ \text { 'A criança é esperta.' } & \end{array}$

\title{
Considerações finais
}

Portanto, podemos concluir sobre a natureza dos lexemas que expressam qualidades em Xavante que, uma vez analisadas as propriedades morfossintáticas das principais classes lexicais da língua, percebe-se que as noções tipicamente expressas por adjetivos nas línguas onde esta categoria existe estão lexicalizadas numa subclasse verbal ${ }^{17}$, e que esta tem possivelmente uma origem nominal. Na ausência de adjetivos, a atribuição de uma qualidade a um nome se faz por composição ou por relativização, sendo que a primeira operação sofre restrições semânticas enquanto a segunda é sempre produtiva.

\section{Abreviações}

ABS

APL.N

AUX

COL

CONJ

DAT

DEM
Absolutivo

Aplicativo nominal

Auxiliar

Coletivo

Conjunção

Dativo

Demonstrativo
INESS Inessivo

INSTR Instrumental

IRR Irrealis

N Forma nominal

NEG Negação

NGR Nome genérico relacional

NMZ Nominalizador

\footnotetext{
${ }^{17}$ Chegamos à mesma conclusão que Cunha de Oliveira (2003) sobre esta questão em Apinajé, língua também do tronco macro-jê.
} 


$\begin{array}{llll}\text { DIM } & \text { Diminutivo } & \text { NOM } & \text { Nominativo } \\ \text { DISTR } & \text { Distributivo } & \text { PE } & \text { Partícula de ênfase } \\ \text { EGO } & \text { Egofórico } & \text { PFT } & \text { Perfeito } \\ \text { ERG } & \text { Ergativo } & \text { PI } & \text { Partícula interrogativa } \\ \text { EXIST } & \text { Existencial } & \text { PL } & \text { Plural } \\ \text { EXPL } & \text { Expletivo } & \text { PR } & \text { Pronome } \\ \text { FOC } & \text { Foco } & \text { PRO } & \text { Projetivo } \\ \text { GNQ } & \text { Genérico } & \text { PROG } & \text { Progressivo } \\ \text { H } & \text { Honorífico } & \text { PROSP } & \text { Prospectivo } \\ \text { HTO } & \text { Heterofórico } & \text { PVB } & \text { Prevérbio } \\ \text { IMP } & \text { Sujeito Impessoal } & \text { SG } & \text { Singular } \\ \text { INC } & \text { Incoativo } & & \end{array}$

\section{REFERÊNCIAS}

CUNHA DE OLIVEIRA, C. Lexical Categories and the Status of Descriptives in Apinajé. International Journal of American Linguistics, v.69, n.3, 2003. p.243-274.

DIXON, R. Where have all the adjectives gone? Berlin: Mouton Publishers, 1982.

HASPELMATH, M. Word-class-changing inflection and morphological theory. In: BOOIJ, G.; VAN MARLE, J. (Ed.). Yearbook of Morphology 1995. Dordrecht: Kluwer Academic Publishers, 1996. p.43-66.

LACHNITT, G. Damreme'uwaimramidzé: estudos sistemáticos e comparativos de gramática xavante. 2 ed. Campo Grande: Missão Salesiana de Mato Grosso Universidade Católica Dom Bosco, 1999.

MCLEOD, R.; MITCHELL, V. Aspectos da língua xavante. Cuiabá: SIL, 2003. Disponível em: 〈http://www.sil.org/americas/brasil/publcns/dictgram/xvgram.pdf>.

MEL'ČUK, I. Cours de morphologie générale. Cinquième partie: signes morphologiques. Montréal: Presses de l'Université de Montréal; CNRS Éditions, 1997. OLIVEIRA, R. Morfologia e sintaxe da língua xavante. Tese de doutorado, Rio de Janeiro: UFRJ - FL, 2007. 
QUEIXALÓS, F. Posse em katukína e valência dos nomes. In: RODRIGUES, A.; CABRAL, A. Novos estudos sobre línguas indígenas. Brasília: Editora Universidade de Brasília, 2005. p.177-202.

RIBEIRO, E. Subordinate Clauses in Karajá. Boletim do Museu Paraense Emílio Goeldi Ciências Humanas, v.1, n.1, p.17-47, 2006.

SALANOVA, A. Relative clauses in Mẽbengokre. In: GIJN, R., HAUDE, K.; MUYSKEN, P. (Eds.). Subordination in Native South American Languages. Amsterdam: John Benjamins, 2011. p.45-78.

TOURNADRE, N. Personne et médiatifs en tibétain. Faits de langues, v.2, n.3, 1994. p.149-158.

VAN TIEN NGUYEN, É. Unité lexicale et morphologie en chinois mandarin: vers l'élaboration d'un dictionnaire explicatif et combinatoire du chinois. Tese (Doutorado) Faculté des études supérieures. Université de Montréal, Montréal, 2006.ok 